\title{
Comparing two regimens of intravaginal misoprostol with intravaginal gemeprost for second- trimester pregnancy termination: a randomised controlled trial
}

\author{
Daniel Seow Choon Koh, ${ }^{1}$ Esther Pei Jing Ang, ${ }^{2}$ Jurja Chua Coyuco, ${ }^{2}$ \\ Hua Zhen Teo, ${ }^{3}$ Xiaoling Huang, ${ }^{3}$ Xing Wei, ${ }^{4}$ Mor Jack Ng, ${ }^{5}$ \\ Serene Liqing Lim, ${ }^{6}$ Kok Hian $\operatorname{Tan}^{7}$
}

For numbered affiliations see end of article.

\section{Correspondence to}

Dr Daniel Seow Choon Koh, Department of Maternal Fetal Medicine, KK Women's and Children's Hospital, Singapore 229899; daniel.koh.sc@kkh. com.sg

Received 17 October 2016 Revised 21 February 2017 Accepted 20 March 2017 Published Online First 21 April 2017

\section{Linked}

- http://dx.doi.org/10.1136/ jfprhc-2017-101907

CrossMark

To cite: Koh DSC, Ang EPJ,

Coyuco JC, et al. J Fam Plann Reprod Health Care

2017:43:252-259.

\section{ABSTRACT}

Aim To compare the efficacy and safety of intravaginal misoprostol $200 \mu \mathrm{g}, 400 \mu \mathrm{g}$ and gemeprost regimens for second-trimester termination of pregnancy (TOP).

Methods A three- armed randomi sed controlled trial (Clinical Trial Certificate 1100015) where 116 women undergoing second-trimester TOP were given intravaginal misoprostol $200 \mu \mathrm{g}(n=37)$, misoprostol 400 $\mu \mathrm{g}(n=40)$ or gemeprost $1 \mathrm{mg}(n=39)$ at 4hour intervals until abortion occurred with a maximum of five doses.

Results The misoprostol $400 \mu \mathrm{g}$ group had the highest incidence of successful abortions $(92.5 \%)$ compared to the misoprostol 200 $\mu \mathrm{g}(70.3 \% ; p=0.017)$ and gemeprost $1 \mathrm{mg}$ (74.4\%; $p=0.037$ ) within 48 hours. There was no significant difference in abortion rate between misoprostol $200 \mu \mathrm{g}$ and gemeprost. The misoprostol $400 \mu \mathrm{g}$ group had the highest incidence of fever $(70.0 \%)$ compared to misoprostol $200 \mu \mathrm{g}$ (24.3\%; $p<0.001)$ and gemeprost $1 \mathrm{mg}(46.2 \%$; $p=0.041)$. The gemeprost group had the highest incidence of diarrhoea (38.5\%) compared to misoprostol $400 \mu \mathrm{g}(10.0 \%$; $p=0.004)$ and misoprostol $200 \mu \mathrm{g}(8.1 \%$; $p=0.003$ ) groups.

Conclusions Intravaginal misoprostol 400 $\mu \mathrm{g}$ at 4- hour intervals was the most effective regimen but was associated with a high incidence of fever. Misoprostol 200 $\mu \mathrm{g}$ demonstrated similar effectiveness as gemeprost and had lower incidence of diarrhoea. Gemeprost should not be first line for medical therapy given the cost, storage requirements and lower efficacy.

\section{DISCLOSURE OF INTERESTS}

All the authors warrant that they have no financial affiliation or involvement within any commercial organisation with a potential financial interest in the subject or materials discussed in this article. No funding was received for this clinical trial.

\section{AUTHORS' NOTE}

Some of the results presented here have previously appeared in an abstract booklet: Koh SCD, Ang EPJ, Lim SL, Coyuco JC, Teo HZ, Huang X, Tan KH. A randomised controlled trial comparing two intravaginal misoprostol regimens and gemeprost for mid-trimester termination of pregnancy. BJOG 2015; 122 Suppl. 1:83. RCOG World Congress, 2015, Brisbane, QLD, Australia.

\section{INTRODUCTION}

Prostaglandins (PGs) and their analogues play an important role in termination of pregnancy (TOP). In particular, $\mathrm{PGE}_{1}$ analogues such as misoprostol and gemeprost are preferred because of their selectivity for the myometrium and fewer gastrointestinal side effects. $^{1}$

Gemeprost (16, 16-dimethyl-transd2-PGE1 methyl ester) is licensed for second-trimester TOP. It is used as the primary agent for second-trimester TOP at the largest tertiary hospital for women and children (KK Women's and Children's Hospital) in Singapore. Common side effects include vomiting, diarrhoea and fever. ${ }^{2}$ It is expensive (USD 51.27/ pessary) and requires storage at $-10^{\circ} \mathrm{C}$. 
Misoprostol (15-deoxy-16-hydroxy-16-methyl PGE1) is licensed for the treatment of peptic ulcer disease induced by nonsteroidal anti-inflammatory drugs. ${ }^{3}$ It is commonly used outside its licensed indication as an abortifacient. ${ }^{45}$ Misoprostol is available as an oral tablet, is inexpensive (USD 2.01/tablet) and can be kept at room temperature. ${ }^{4-8}$ Pharmacokinetic and clinical studies ${ }^{9}$ have shown that vaginal administration of misoprostol demonstrates better efficacy in TOP compared with oral administration. ${ }^{10}$ The common side effects are dose-dependent ${ }^{11}$ and include nausea, vomiting, diarrhoea, abdominal pain, chills and fever. ${ }^{11}$ Fever is a side effect common of both gemeprost and misoprostol as prostaglandins interfere with the hypothalamus by a shift in temperature set point, resulting in a systemic response of increased body temperature. ${ }^{12}$

When used as monotherapy, misoprostol can achieve successful abortion rates ranging from 38.5\% to $98 \% .^{4913}$ A Cochrane review ${ }^{6}$ concluded that the optimal route for administrating misoprostol is vaginally at 3 -hour intervals. Doses of 100 or $200 \mu \mathrm{g}$ misoprostol every 6 or 12 hours, respectively, was inferior to gemeprost in terms of induction-to-abortion interval. ${ }^{6}$ When the dose interval for $400 \mu \mathrm{g}$ misoprostol was 3 hours instead of 6 hours, the interval to abortion was shorter. ${ }^{6}$ A review by Allen et al. ${ }^{14}$ concluded that superiority of one dose or schedule over another could not be clearly drawn from available studies. In a direct comparison study, Dickinson et al. ${ }^{15}$ showed that regimens using misoprostol 200 $\mu \mathrm{g}$ and gemeprost resulted in similar incidences of abortions. Hence, misoprostol $200 \mu \mathrm{g}$ and $400 \mu \mathrm{g}$ at 4-hour intervals were selected for comparison with our hospital's protocol of gemeprost $1 \mathrm{mg}$ every 4 hours to determine the optimal PGE1 analogue and regimen for second-trimester TOP.

While mifepristone is commonly used in combination with misoprostol for TOP, it was not registered in Singapore at the commencement of this trial and hence was not included in the study design.

The primary objective was to compare the incidence of successful abortions within 48 hours among the misoprostol $200 \mu \mathrm{g}$ and $400 \mu \mathrm{g}$ and gemeprost $1 \mathrm{mg}$ groups in second-trimester TOP. The secondary objectives were to compare the induction-to-abortion intervals and the side effect profiles among the three groups.

\section{METHODS}

This study was reviewed and approved by the hospital's ethics committee, the SingHealth Centralised Institution Review Board on 12 November 2010 (CIRB Reference Number: 2010/591/D). The Clinical Trial Certificate (CTC 1100015 11/01/2011-10/01/2013), which is required for all clinical trials on medicinal products conducted in Singapore, was issued by the Health Sciences Authority of Singapore.
Healthy women with singleton pregnancies and no uterine scars who presented for TOP at a gestational age of 13 to 23 completed weeks from the period of December 2010 to May 2012 were invited to participate in the study at the Division of Obstetrics and Gynaecology of KK Women's and Children's Hospital by the study co-investigators. These women were counselled by licensed abortion counsellors and written consent was taken after at least 48 hours in accordance with the TOP Act (Chapter 324) of Singapore. Termination of pregnancy beyond 23 completed weeks is not permitted under the TOP Act of Singapore. The exclusion criteria were women with signs or symptoms of spontaneous abortion (vaginal bleeding and/or contractions), intrauterine fetal death, medical contraindications to trial medications, and other serious medical conditions such as poorly-controlled asthma, cardiovascular disease, uncontrolled hypertension or diabetes, liver or kidney dysfunction, seizure disorders, glaucoma, uncontrolled hyperthyroidism, gynaecological infections, severe anaemia and coagulopathies.

The study design is summarised in Figure 1.

Written informed consent was obtained from participants. Demographic data were recorded at the time of recruitment. A pelvic ultrasound examination was performed to determine the stage of the gestation and to exclude multiple pregnancies and missed miscarriages.

Participants were randomised using sealed, opaque and unmarked envelopes randomly drawn out by the participants themselves, into three treatment groups: misoprostol 200 and $400 \mu \mathrm{g}$ (Cytotec $200 \mu \mathrm{g}$ tablet; Piramal Healthcare UK Limited, UK) and gemeprost (Cervagem; Ono Pharmaceutical Co. Ltd, Japan) $1 \mathrm{mg}$. The trial medication was inserted into the posterior vaginal fornix at 4-hour intervals until expulsion of the fetus with a maximum of five doses. Participants were observed for 48 hours from the time of insertion of the first dose of medication. This study was single-blinded. Participants were not informed of their assigned treatment throughout the study.

Successful abortion was defined as the expulsion of the fetus and placenta without surgical assistance within the stipulated observation period of 48 hours. All participants were discharged from the study after 48 hours. Participants who failed to abort after 48 hours were managed in accordance with the hospital's protocol, which involved the administration of a second course of five doses of gemeprost $1 \mathrm{mg}$ at 4-hour intervals 24 hours after the last dose of trial medication.

The induction-to-abortion time interval was defined as the time from the administration of the first dose of trial medication until fetal expulsion. It was only determined for patients who successfully aborted by the stipulated 48-hour observation period.

Each women was asked at the end of the study to respond with either a 'Yes' or 'No' to each side effect. 


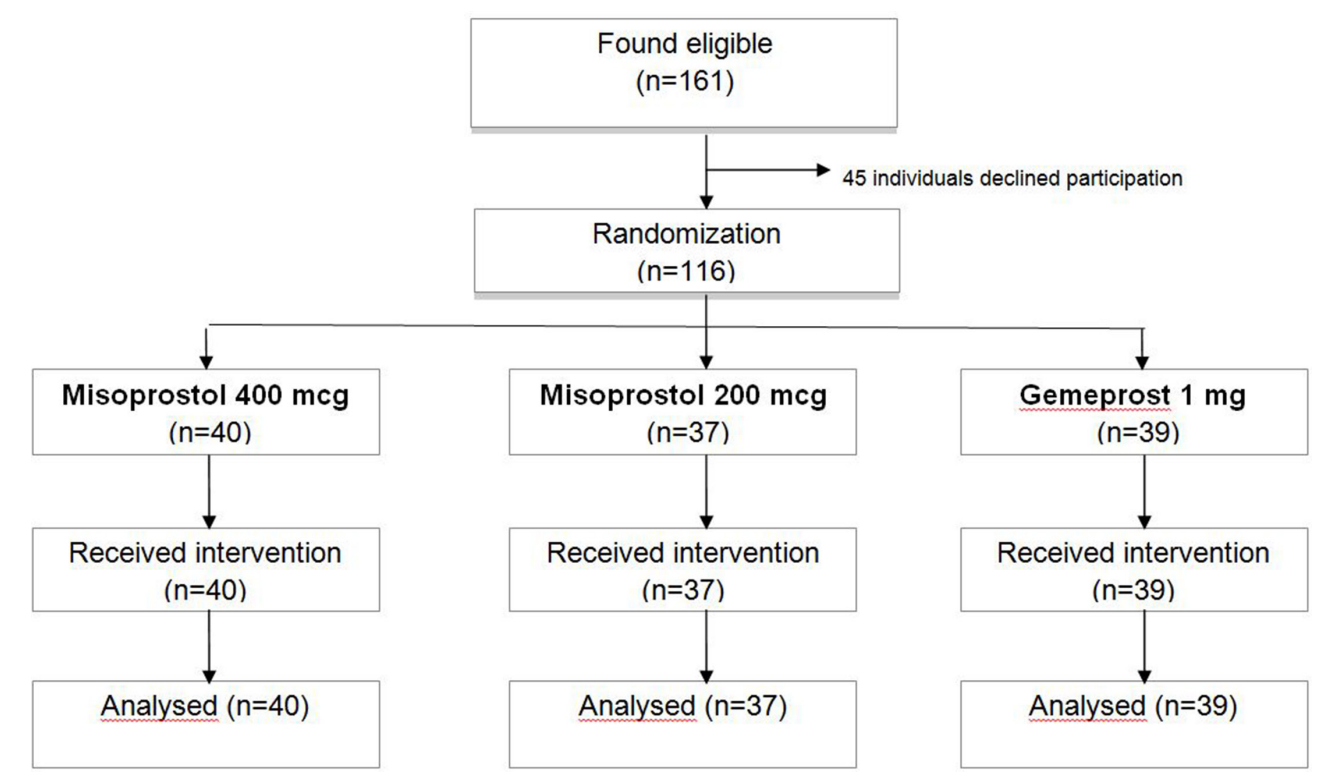

Figure 1 Study flow diagram.

Those side effects that could be quantified were taken from the nursing notes. Data on analgesia requirements and other side effects experienced by the participants attributable to the trial medications was collected. Fever was defined as a temperature $\geq 37.6^{\circ} \mathrm{C}$ on two consecutive measurements or $\geq 38.0^{\circ} \mathrm{C}$ on one measurement. Paracetamol was given to women with fever. The pain experienced was assessed using a visual analogue scale and the maximum score was recorded.

inThe sample size for the study was calculated to be 37 patients for each group based on a two-group comparison using Fisher's exact test, assuming successful abortion rates of $86 \%{ }^{16}$ and $58 \%{ }^{7}$ for misoprostol $400 \mu \mathrm{g}$ and gemeprost groups, with a power of $80 \%$ at a $5 \%$ level of significance. Differences in continuous variables among the three groups were analysed with one-way analysis of variance (ANOVA) and Kruskal-Wallis test where appropriate. If the difference was significant, pairwise comparison was performed using Student's $t$-test or Wilcoxon rank-sum test. Fisher's exact test was used to analyse the difference in the distribution of categorical variables among groups. A $p$ value less than 0.05 was considered statistically significant. All statistical analyses were performed using SPSS 19 (IBM, Armonk, NY, USA.).

\section{RESULTS}

A total of 161 women were invited to participate in the study. The response rate was 72\%. A total of 116 women were included in the final analysis. All baseline demographics were comparable among the groups (Table 1).

The misoprostol $400 \mu \mathrm{g}$ group had the highest incidence of successful abortions within 48 hours: $92.5 \%$ versus $70.3 \%$ in the misoprostol $200 \mu \mathrm{g}$ group $(p=0.017)$ and $74.4 \%$ in the gemeprost group $(p=0.037)$ (Table 2). There was no significant difference in the incidence of successful abortions between the misoprostol $200 \mu \mathrm{g}$ and gemeprost groups.

In the subgroup of nulliparous women, the misoprostol $400 \mu \mathrm{g}$ group had a higher incidence of successful abortions of $91.7 \%$ compared with $60 \%$ in the gemeprost group $(p=0.027)$. In the subgroup of parous women, a significant difference in the incidence of successful abortions was detected among the groups. However, further analysis using pairwise comparison between the groups failed to demonstrate a significant difference. There was no significant difference in the successful abortion rates between the misoprostol 200 $\mu \mathrm{g}$ and gemeprost groups in the subgroup analyses.

There was no significant difference in the median induction-to-abortion intervals between all regimens of misoprostol and gemeprost and in the subgroups of nulliparous or parous women (Figure 2).

\begin{tabular}{llll}
\hline Table 1 & Baseline demographics of subjects \\
\hline & $\begin{array}{l}\text { Misoprostol } \\
\mathbf{4 0 0} \boldsymbol{\mu g} \\
(\boldsymbol{n}=\mathbf{4 0})\end{array}$ & $\begin{array}{l}\text { Misoprostol } \\
\mathbf{2 0 0} \boldsymbol{\mu g} \\
(\boldsymbol{n}=\mathbf{3 7})\end{array}$ & $\begin{array}{l}\text { Gemeprost } \\
\mathbf{1 ~ m g} \\
(\boldsymbol{n}=39)\end{array}$ \\
\hline Characteristic
\end{tabular}

Values are expressed as mean ( \pm standard deviation) for continuous variables or number (percentage) for categorical variables.

BMI, body mass index; TOP, termination of pregnancy. 
Table 2 Successful abortion rates for the three treatment groups

\begin{tabular}{|c|c|c|c|c|c|c|c|}
\hline & $\begin{array}{l}\text { Miso-prostol } \\
400 \mu \mathrm{g} \\
(n=40)\end{array}$ & $\begin{array}{l}\text { Miso-prostol } \\
200 \mu \mathrm{g} \\
(n=37)\end{array}$ & $\begin{array}{l}\text { Geme-prost } \\
1 \mathrm{mg} \\
(n=39)\end{array}$ & $p$ & $\begin{array}{l}p \\
\text { (misoprostol } \\
400 \mu \mathrm{g} \\
\text { vs } \\
\text { gemeprost) }\end{array}$ & $\begin{array}{l}p \\
\text { (misoprostol } \\
200 \mu \mathrm{g} \\
\text { vs } \\
\text { gemeprost) }\end{array}$ & $\begin{array}{l}p \\
\text { (misoprostol } \\
400 \mu g \text { vs } \\
\text { misoprostol } \\
200 \mu g \text { ) }\end{array}$ \\
\hline Successful abortion & $37(92.5 \%)$ & $26(70.3 \%)$ & $29(74.4 \%)$ & $0.027^{*}$ & $0.037^{*}$ & 0.799 & $0.017^{*}$ \\
\hline \multicolumn{8}{|c|}{ Subgroup analyses: } \\
\hline Nulliparous ( $n=47$ ) & $22(91.7 \%)$ & $13(81.3 \%)$ & $12(60.0 \%)$ & $0.037^{*}$ & $0.027^{*}$ & 0.277 & 0.373 \\
\hline Parity $\geq 1 \quad(n=45)$ & $15(93.8 \%)$ & $13(61.9 \%)$ & $17(89.5 \%)$ & $0.037^{*}$ & 1.000 & 0.069 & 0.050 \\
\hline
\end{tabular}

Values are expressed as number (percentage).

*Statistically significant.

All successful abortions in the misoprostol 400 $\mu \mathrm{g}$ group occurred within 32 hours compared with 39 hours in the misoprostol $200 \mu \mathrm{g}$ group and 42 hours in the gemeprost group (Figure 3).

The misoprostol $400 \mu \mathrm{g}$ group had the highest incidence of fever: $70.0 \%$ versus $24.3 \%$ in the misoprostol $200 \mu$ group $(p<0.001)$ and $46.2 \%$ in the gemeprost $1 \mathrm{mg}$ group $(p=0.041)$ (Table 3$)$.

The gemeprost $1 \mathrm{mg}$ group had the highest incidence of diarrhoea: $38.5 \%$ in the gemeprost $1 \mathrm{mg}$ group versus $10.0 \%$ in the misoprostol $400 \mu \mathrm{g}$ group $(p=0.004)$ and $8.1 \%$ in the misoprostol $200 \mu$ g group $(p=0.003)$ (Table 3). Among the three groups, the misoprostol $200 \mu \mathrm{g}$ group had the lowest incidences of fever and diarrhoea. There was no significant difference among all groups for the other side effects listed in Table 3. There was also no difference in pain scores, or analgesia requirements among participants in the three groups. There was no incidence of uterine rupture or serious complications in any of the three groups.

\section{DISCUSSION}

The misoprostol $400 \mu \mathrm{g}$ group had the highest incidence of successful abortions, at $92.5 \%$ within 48 hours from the administration of the first dose. The success rate in this group was $80 \%$ at the 24 -hour mark from the administration of the first dose as illustrated in Figure 3. This 24-hour success rate is comparable to

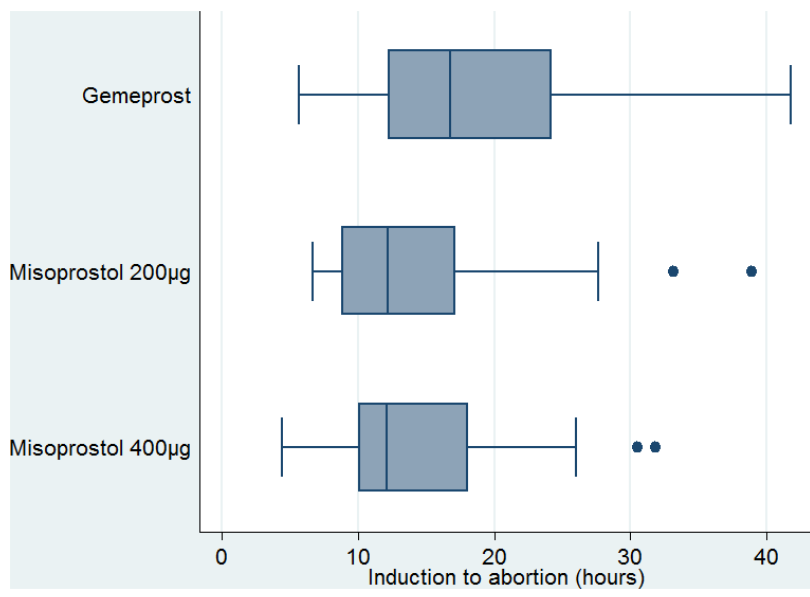

Figure 2 Median induction-to-abortion time for the three treatment groups. the abortion rates reported in the studies by Su et al. ${ }^{13}$ Wong et al. ${ }^{717}$ and Tang et al. ${ }^{16}$ where misoprostol $400 \mu \mathrm{g}$ was administered at 3-hour intervals, up to five doses and abortion occurring within a 24-hour time interval. The abortion rates of these studies ranged from $73 \%$ to $86 \%$.

The finding that higher abortion rates were obtained with misoprostol $400 \mu \mathrm{g}$ compared with gemeprost is supported by Wong et al. ${ }^{7}$ who demonstrated that misoprostol $400 \mu \mathrm{g}$ at 3-hour intervals up to a maximum of five doses resulted in a significantly higher incidence of abortions ( $80 \%$ vs $58.6 \%$; $p=0.006$ ) within 24 hours compared with gemeprost $1 \mathrm{mg}$ at 3 -hour intervals. Other gemeprost and misoprostol direct comparison trials which did not demonstrate superiority of misoprostol over gemeprost consistently used vaginal misoprostol at lower doses than the current trial: $200 \mu \mathrm{g}$ at 6-hour intervals in the study by Dickinson et al. ${ }^{15} ; 100$ $\mu \mathrm{g}$ at 6 -hour and $200 \mu \mathrm{g}$ at 12 -hour intervals in the study by Nuutila et al. ${ }^{18}$

There was no significant difference between the incidence of successful abortions in the misoprostol 200 $\mu \mathrm{g}$ and the gemeprost group at 48 hours. The success rates of the misoprostol $200 \mu \mathrm{g}$ and the gemeprost group at the 24-hour mark from the administration of the first dose were $59.5 \%$ and $53.8 \%$, respectively, as shown in Figure 3. In a similar study, Dickinson et al. ${ }^{15}$ reported no significant difference in the incidence of successful abortions within 24 hours when misoprostol $200 \mu \mathrm{g}$ was given 6-hour and when gemeprost $1 \mathrm{mg}$ was given 3-hour, up to a maximum of five doses.

In the subgroup of nulliparous women, the misoprostol $400 \mu \mathrm{g}$ group resulted in a higher incidence of abortions compared with gemeprost; there was no difference in the parous subgroup. This finding has been previously observed in a misoprostol and gemeprost direct comparison study ${ }^{7}$ and supports the selection of misoprostol in nulliparous women. However, this result should be interpreted with caution as the sample size in the parous subgroup may not be sufficiently powered to detect a significant difference.

The median induction-to-abortion intervals were similar among all groups in this study. The interval of 12.1 hours in the misoprostol $400 \mu \mathrm{g}$ group is comparable to intervals reported in other studies 


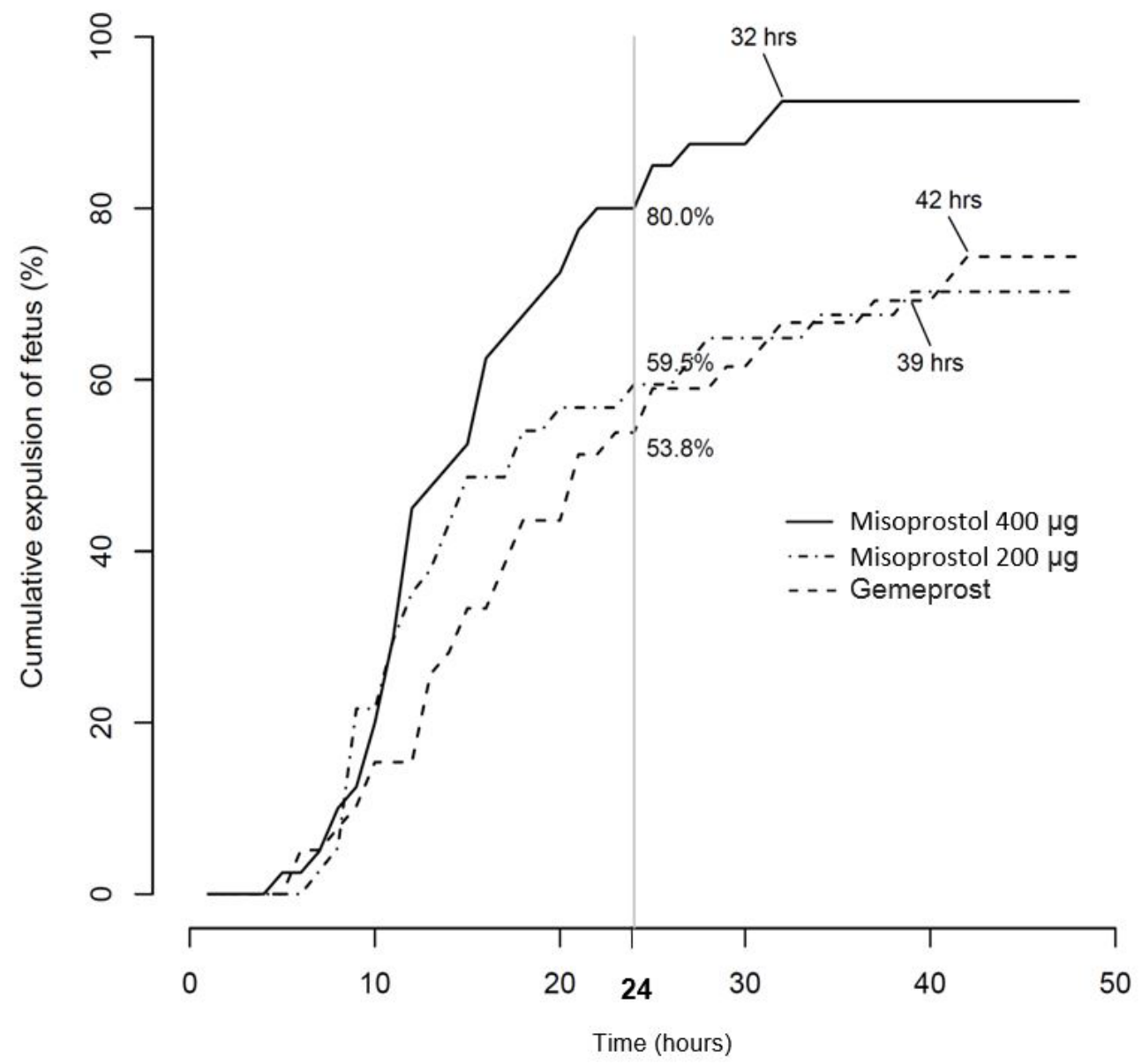

Figure 3 Cumulative expulsion of fetus for each of the three regimens over time.

using five doses of misoprostol $400 \mu \mathrm{g}$ at 3-hour intervals in 24 hours. These intervals ranged from 10.5 to 16.2 hours. ${ }^{7} 1317-19$

The median induction-to-abortion intervals and incidence of successful abortions in this study were comparable with other studies using a 3-hour interval. ${ }^{713} 1617$ This can be explained by the pharmacokinetic profile of misoprostol. According to Zieman et al. ${ }^{19}$ the plasma concentration of misoprostol acid, following the administration of vaginal misoprostol $400 \mu \mathrm{g}$, peaks at 80 minutes. It then slowly declines to $60 \%$ of the peak concentration at 4 hours after administration. ${ }^{17}$ The duration of action of vaginal misoprostol has been estimated to be 4 hours. ${ }^{10}$ These could account for the similar success rates observed using 3- and 4-hour intervals. Findings from this study support the use of a 4-hour misoprostol regimen for abortion.

The median induction-to-abortion interval of 12.2 hours in the misoprostol $200 \mu \mathrm{g}$ group in this study appeared to be shorter than intervals reported in other similar studies. ${ }^{15} 20$ The median induction-to-abortion intervals were found to be $16.9^{15}$ and 18.2 hours $^{20}$ in two studies on women who were given intravaginal misoprostol $200 \mu \mathrm{g}$ at 6-hour intervals up to a maximum duration of 48 hours.

Oral administration of mifepristone 36 to 48 hours before prostaglandin analogues is routinely recommended for medical abortion between 13 and 24 weeks of gestation. ${ }^{21}$ The prior use of mifepristone is associated with shorter induction-to-abortion intervals with subsequent prostaglandin analogue use. ${ }^{22} 23$ In the study by Kapp et al. ${ }^{22}$ comparing the effect of misoprostol and mifepristone with misoprostol only, the addition of mifepristone in second-trimester abortion reduced the induction-to-abortion interval from 18 hours [95\%confidence interval (CI) 1-22] to 10 hours $(95 \% \mathrm{CI} 8-12)$. This induction-to-abortion interval was preceded by a 20-24-hour wait after mifepristone or placebo was taken in the comparison groups. $^{22}$ This was similar to the study by Ngoc et al. ${ }^{23}$ who compared pretreatment with mifepristone $200 \mu \mathrm{g}$ followed by misoprostol 1 day later with misoprostol alone for second-trimester abortion. The addition of mifepristone reduced the mean induction-to-abortion interval from 10.6 hours [standard deviation (SD) 2.5] to 8.1 hours (SD 2.8); $p<0.001$ ). These induction-to-abortion intervals did not account for the time needed to elapse after the mifepristone dose. The median induction-to-abortion intervals ranging from 12.1 to 16.8 hours achieved in this study using prostaglandin analogue-only regimes suggest that mifepristone may not be necessary to shorten induction-to-abortion intervals. 
In the subgroup analysis, there was no statistical difference in the induction-to-abortion time between the nulliparous and the parous women. However, this finding differs from a previous study that supports shorter induction-to-abortion interval in the primiparous group. This may be because the sample size in our subgroup may not be sufficiently powered to detect a significant difference.

Side effects experienced by women in this study were generally transient and minor and did not differ among groups, aside from the incidence of fever and diarrhoea, which was lowest with the misoprostol 200 $\mu \mathrm{g}$ regimen. Fever is a dose-dependent side effect of misoprostol. ${ }^{12}$ In a retrospective study involving 403 women undergoing TOP with a comparable misoprostol regimen, up to $42 \%$ of the women developed fever. ${ }^{12}$ In our study, the misoprostol $400 \mu \mathrm{g}$ regimen resulted in the highest incidence of fever of $70 \%$. A possible reason for this difference may be due to the use of $37.8^{\circ} \mathrm{C}$ and above as a definition of fever.

A higher incidence of diarrhoea was observed in the gemeprost group compared with the misoprostol groups. The fever and diarrhoea, however, was transient and self-limiting. These findings are consistent with those reported by Wong et al. ${ }^{7}$ using similar regimens.
There was no uterine rupture, pelvic infections or other serious complications in this study. This study was not sufficiently powered to detect the occurrence of uterine rupture as it is a rare complication in second-trimester TOP with an estimated incidence of $0.04 \%$ for women without prior caesarean delivery. ${ }^{24}$

This study excluded women with uterine scar; hence it was unable to provide evidence of safety in this population. Mifepristone is not registered in Singapore and hence was not considered as a treatment option in this study.

Intravaginal misoprostol $400 \mu \mathrm{g}$ when administered at 4-hour intervals was the most effective regimen for second-trimester TOP in our study. Although it was associated with a high incidence of fever, this was transient and self-limiting. The misoprostol $200 \mu \mathrm{g}$ regimen demonstrated similar effectiveness as the gemeprost regimen and had lower incidence of fever compared with the misoprostol $400 \mu \mathrm{g}$ regimen and diarrhoea compared with the gemeprost regimen. Gemeprost should not be used as first line for medical abortion given the cost, practical issues posted by storage requirements and the relative lower efficacy compared wtih misoprostol $400 \mu \mathrm{g}$ regimen.

Table 3 Incidence of side effects and analgesia requirements

\begin{tabular}{|c|c|c|c|c|c|c|c|}
\hline Side effects & $\begin{array}{l}\text { Misoprostol } \\
400 \mu \mathrm{g} \\
(n=40)\end{array}$ & $\begin{array}{l}\text { Misoprostol } \\
200 \mu \mathrm{g} \\
(n=37)\end{array}$ & $\begin{array}{l}\text { Gemeprost } \\
1 \mathrm{mg} \\
(n=39)\end{array}$ & $p$ & $\begin{array}{l}p \\
\text { (misoprostol } \\
400 \mu \mathrm{g} \\
\text { vs } \\
\text { gemeprost) }\end{array}$ & $\begin{array}{l}p \\
\text { (misoprostol } \\
200 \mu \mathrm{g} \\
\text { vs } \\
\text { gemeprost) }\end{array}$ & $\begin{array}{l}p \\
\text { (misoprostol } \\
400 \mu \mathrm{g} \text { vs } \\
\text { misoprostol } \\
200 \mu \mathrm{g} \text { ) }\end{array}$ \\
\hline Nausea & $11(27.5 \%)$ & $10(27.0 \%)$ & $16(41.0 \%)$ & 0.344 & & & \\
\hline Vomiting & $12(30.0 \%)$ & $12(32.4 \%)$ & $13(33.3 \%)$ & 0.968 & & & \\
\hline Backache & $17(42.5 \%)$ & $13(35.1 \%)$ & $19(48.7 \%)$ & 0.500 & & & \\
\hline $\begin{array}{l}\text { Muscle } \\
\text { weakness }\end{array}$ & $6(15.0 \%)$ & $6(16.2 \%)$ & $3(7.7 \%)$ & 0.512 & & & \\
\hline Dizziness & $7(17.5 \%)$ & $6(16.2 \%)$ & $4(10.3 \%)$ & 0.643 & & & \\
\hline Flushing & $10(25.0 \%)$ & $10(27.0 \%)$ & $6(15.4 \%)$ & 0.430 & & & \\
\hline Chills & $20(50.0 \%)$ & $15(40.5 \%)$ & $19(48.7 \%)$ & 0.693 & & & \\
\hline Chest pains & $0(0.0 \%)$ & $2(5.4 \%)$ & $1(2.6 \%)$ & 0.208 & & & \\
\hline Fever & $28(70.0 \%)$ & $9(24.3 \%)$ & $18(46.2 \%)$ & $<0.001^{*}$ & $0.041^{*}$ & 0.058 & $<0.001^{*}$ \\
\hline Palpitations & $3(7.5 \%)$ & $3(8.1 \%)$ & $5(12.8 \%)$ & 0.729 & & & \\
\hline $\begin{array}{l}\text { Diarrhoea ( } \geq 2 \\
\text { loose stools) }\end{array}$ & $4(10.0 \%)$ & $3(8.1 \%)$ & $15(38.5 \%)$ & $0.001^{*}$ & $0.004^{*}$ & $0.003^{*}$ & 1.000 \\
\hline $\begin{array}{l}\text { Abdominal } \\
\text { cramps }\end{array}$ & $12(30.0 \%)$ & $5(13.5 \%)$ & $12(30.8 \%)$ & 0.135 & & & \\
\hline \multicolumn{8}{|l|}{ Pain } \\
\hline $\begin{array}{l}\text { No analgesic } \\
\text { use }\end{array}$ & $2(5.0 \%)$ & $4(10.8 \%)$ & $4(10.3 \%)$ & 0.654 & & & \\
\hline Opioid use & $8(20.0 \%)$ & $12(32.4 \%)$ & $14(35.9 \%)$ & 0.266 & & & \\
\hline Pain scoret & $6.1(2.8)$ & $4.8(2.9)$ & $5.9(2.9)$ & 0.123 & & & \\
\hline None & $2(5.0 \%)$ & $4(10.8 \%)$ & $2(5.1 \%)$ & 0.590 & & & \\
\hline
\end{tabular}




\section{STUDY STRENGTHS}

This is a unique study where we performed a direct comparison of three established regimens of abortifacients. Existing trials only performed direct comparison of up to two of these regimens ${ }^{71315-182023}$ and not all three regimens.

This study also had active participation from the Department of Pharmacy in our institution. This ensured that the storage conditions of trial medications were strictly adhered to.

\section{STUDY LIMITATIONS}

Our hospital protocol requires all patients undergoing second-trimester TOP to undergo surgical evacuation. Therefore, this study was unable to assess the completeness of abortion using $\mathrm{PGE}_{1}$ analogues alone. This study also excluded women with previous uterine scar; hence it was unable to provide information in population with scarred uterus.

This study was not powered to detect differences stratified by parity in the subgroup analysis. Therefore, results of the subgroup analysis should be interpreted with caution.

Blood loss was not measured objectively using haemoglobin levels pre- and post-insertion of the trial medications. This information was not obtained as tests for haemoglobin levels post-abortion are not routinely performed in our institution unless clinically indicated.

\section{Ethical approval}

All procedures performed in studies involving human participants were in accordance with the ethical standards of the institutional and/or national research committee and with the 1964 Helsinki declaration and its later amendments or comparable ethical standards.

Clinical Trial Registration Number: CTC1100015

Registry website: https://eservice.hsa.gov.sg/prism/ct _r/enquiry.do?action = getAllTherapeuticArea

The Clinical Trials Register on HSA website lists active clinical trials from our Clinical Trial Certificate (CTC) applications database. The information on the clinical trial is published on the Clinical Trials Register from the CTC approval date, until the expiry date of the CTC.

Based on the CTC approval date (Section 1.4) and expiry date (Section 1.5) for this clinical trial (see attached CTC), the trial was previously published on the Clinical Trials Register from 11/01/2011-10/01/2013.)

\section{Author affiliations}

${ }^{1}$ Associate Consultant, Division of Obstetrics \& Gynecology, KK Women's and Children's Hospital, Singapore, Singapore

${ }^{2}$ Pharmacist, Department of Pharmacy, KK Women's and Children's Hospital, Singapore, Singapore

${ }^{3}$ Clinical Pharmacist, Department of Pharmacy, KK Women's and Children's Hospital, Singapore, Singapore

${ }^{4}$ Executive, Department of Maternal Fetal Medicine, KK Women's and Children's Hospital, Singapore, Singapore

${ }^{5}$ Manager, Division of Obstetrics \& Gynecology, OBGYN Academic Clinical Program, KK Women's and Children's Hospital, Singapore, Singapore
${ }^{6}$ Associate Consultant, Division of Surgery, Singapore General Hospital, Singapore, Singapore

${ }_{7}^{7}$ Senior Consultant, Division of Obstetrics \& Gynecology, KK Women's and Children's Hospital, Singapore, Singapore

Contributors Authors CJC and WX have left their service while LSLQ has been transferred to another department before the completion of the study. KSCD, AEPJ, THZ, LSLQ and TKH conceived and designed the study. KSCD, AEPJ, CJC and HXL acquired the data. KSCD, NMJ, WX, AEPJ, THZ and HXL analysed and interpreted the data. KSCD drafted the article. AEPJ, THZ, HXL and TKH critically revised the article.

Competing interests None declared.

Ethics approval SingHealth Centralised Institution Review Board.

Provenance and peer review Not commissioned; externally peer reviewed.

(C) Faculty of Sexual and Reproductive Healthcare of the Royal College of Obstetricians and Gynaecologists (unless otherwise stated in the text of the article) 2017. All rights reserved. No commercial use is permitted unless otherwise expressly granted.

\section{REFERENCES}

1 Bygdaman M. Termination of second trimester pregnancy with laminaria and intramuscular 15-methyl PGF2 alpha or 16-phenoxy-omega-17,18,19,20-tetranor PGE2 methyl sulfonylamide. A randomized multicenter study. Int J Gynaecol Obstet 1988;26:129-135.

2 Cameron IT, Michie AF, Baird DT. Prostaglandin-induced pregnancy termination: further studies using gemeprost $(16,16$ dimethyl-trans-delta 2-PGE1 methyl ester) vaginal pessaries in the early second trimester. Prostaglandins 1987;34:111-117.

3 Weeks A, Faúndes A. Misoprostol in obstetrics and gynecology. Int J Gynaecol Obstet 2007;99:S156-S159.

4 Lalitkumar S, Bygdeman M, Gemzell-Danielsson K. Midtrimester induced abortion: a review. Hum Reprod Update 2007;13:37-52.

5 Shaw D. Misoprostol for reproductive health: dosage recommendations. Int J Gynaecol Obstet 2007;99:S155.

6 Wildschut H, Both MI, Medema S, et al. Medical methods for mid-trimester termination of pregnancy. Cochrane Database Syst Rev 2011;1:CD005216.

7 Wong KS, Ngai CS, Wong AY, et al. Vaginal misoprostol compared with vaginal gemeprost in termination of second trimester pregnancy. A randomized trial. Contraception 1998;58:207-210.

8 Gómez Ponce de León R, Wing DA. Misoprostol for termination of pregnancy with intrauterine fetal demise in the second and third trimester of pregnancy - a systematic review. Contraception 2009;79:259-271.

9 Nigam A, Singh VK, Prakash A. Vaginal vs. oral misoprostol for mid-trimester abortion. Int J Gynaecol Obstet 2006;92:270271.

10 Tang OS, Gemzell-Danielsson K, Ho PC. Misoprostol: pharmacokinetic profiles, effects on the uterus and side-effects. Int J Gynaecol Obstet 2007;99:S160-S167.

11 Goldberg AB, Greenberg MB, Darney PD. Misoprostol and pregnancy. N Engl J Med 2001;344:38-47.

12 Nijman TA, Voogdt KG, Teunissen PW, et al. Association between infection and fever in terminations of pregnancy using misoprostol: a retrospective cohort study. BMC Pregnancy Childbirth 2017;17:7.

13 Su LL, Biswas A, Choolani M, et al. A prospective, randomized comparison of vaginal misoprostol 
versus intra-amniotic prostaglandins for midtrimester termination of pregnancy. Am J Obstet Gynecol 2005;193:1410-1414.

14 Allen R, O'Brien BM. Uses of misoprostol in obstetrics and gynecology. Rev Obstet Gynecol 2009;2:159-68.

15 Dickinson JE, Godfrey M, Evans SF. Efficacy of intravaginal misoprostol in second-trimester pregnancy termination: a randomized controlled trial. J Matern Fetal Med 1998;7:115119.

16 Tang OS, Lau WN, Chan CC, et al. A prospective randomised comparison of sublingual and vaginal misoprostol in second trimester termination of pregnancy. BJOG 2004;111:10011005.

17 Wong KS, Ngai CS, Yeo EL, et al. A comparison of two regimens of intravaginal misoprostol for termination of second trimester pregnancy: a randomized comparative trial. Hum Reprod 2000;15:709-712.

18 Nuutila M, Toivonen J, Ylikorkala O, et al. A comparison between two doses of intravaginal misoprostol and gemeprost for induction of second-trimester abortion. Obstet Gynecol 1997;90:896-900.
19 Zieman M, Fong SK, Benowitz NL, et al. Absorption kinetics of misoprostol with oral or vaginal administration. Obstet Gynecol 1997;90:88-92.

20 Dickinson JE, Evans SF. The optimization of intravaginal misoprostol dosing schedules in second-trimester pregnancy termination. Am J Obstet Gynecol 2002;186:470-474.

21 Royal College of Obstetricians and Gynaecologists (RCOG). The Care of Women Requesting Induced Abortion. Evidencebased Clinical Guideline Number 7. London, UK: RCOG, 2011. Available at. https://www.rcog.org.uk/globalassets/ documents/guidelines/abortion-guideline_web_1.pdf (accessed 6 February 2017).

22 Kapp N, Borgatta L, Stubblefield P, et al. Mifepristone in second-trimester medical abortion: a randomized controlled trial. Obstet Gynecol 2007;110:1304-1310.

23 Ngoc NT, Shochet T, Raghavan S, et al. Mifepristone and misoprostol compared with misoprostol alone for secondtrimester abortion: a randomized controlled trial. Obstet Gynecol 2011;118:601-608.

24 Goyal V. Uterine rupture in second-trimester misoprostolinduced abortion after cesarean delivery: a systematic review. Obstet Gynecol 2009;113:1117-1123. 